\title{
Molecular genetic analysis of FGFR I signalling reveals distinct roles of MAPK and PLC $\gamma$ I activation for self-renewal of adult neural stem cells
}

\author{
Dengke K Ma1,2, Karthikeyan Ponnusamy33, Mi-Ryoung Song2,5, Guo- \\ li Ming1,2,4 and Hongjun Song*1,2,4
}

Address: ${ }^{1}$ Institute for Cell Engineering, Johns Hopkins University School of Medicine, Baltimore, Maryland 21205, USA, ${ }^{2}$ Solomon H. Snyder Department of Neuroscience, Johns Hopkins University School of Medicine, Baltimore, Maryland 21205, USA, ${ }^{3}$ Department of Biomedical Engineering, Johns Hopkins University School of Medicine, Baltimore, Maryland 21205, USA, ${ }^{4}$ Department of Neurology, Johns Hopkins University School of Medicine, Baltimore, Maryland 21205, USA and ${ }^{5}$ Bioimaging Research Center and Cell Dynamics Research Center, Gwangju Institute of Science and Technology, Gwangju 500-712, Republic of Korea

Email: Dengke KMa - dma2@jhmi.edu; Karthikeyan Ponnusamy - k.ponnusamy@stanford.edu; Mi-Ryoung Song - msong@gist.ac.kr; Guoli Ming - gming1@jhmi.edu; Hongjun Song* - shongju1@jhmi.edu

* Corresponding author

Published: 8 June 2009

Molecular Brain 2009, 2:16 doi:10.1186/1756-6606-2-16
Received: 18 May 2009

Accepted: 8 June 2009

This article is available from: http://www.molecularbrain.com/content/2/1/16

(C) 2009 Ma et al; licensee BioMed Central Ltd.

This is an Open Access article distributed under the terms of the Creative Commons Attribution License (http://creativecommons.org/licenses/by/2.0), which permits unrestricted use, distribution, and reproduction in any medium, provided the original work is properly cited.

\begin{abstract}
Background: Neural stem cells (NSCs) are present in the adult mammalian brain and sustain lifelong adult neurogenesis in the dentate gyrus of the hippocampus. In culture, fibroblast growth factor-2 (FGF-2) is sufficient to maintain the self-renewal of adult NSCs derived from the adult rat hippocampus. The underlying signalling mechanism is not fully understood.

Results: In the established adult rat NSC culture, FGF-2 promotes self-renewal by increasing proliferation and inhibiting spontaneous differentiation of adult NSCs, accompanied with activation of MAPK and PLC pathways. Using a molecular genetic approach, we demonstrate that activation of FGF receptor I (FGFRI), largely through two key cytoplasmic amino acid residues that are linked to MAPK and PLC activation, suffices to promote adult NSC self-renewal. The canonical MAPK, ErkI/2 activation, is both required and sufficient for the NSC expansion and anti-differentiation effects of FGF-2. In contrast, PLC activation is integral to the maintenance of adult NSC characteristics, including the full capacity for neuronal and oligodendroglial differentiation.

Conclusion: These studies reveal two amino acid residues in FGFRI with linked downstream intracellular signal transduction pathways that are essential for maintaining adult NSC self-renewal. The findings provide novel insights into the molecular mechanism regulating adult NSC selfrenewal, and pose implications for using these cells in potential therapeutic applications.
\end{abstract}

\section{Background}

Neural stem cells (NSCs) represent a unique type of precursor cells that are capable of self-renewal and differentiation into multiple neural cell types, including neurons and glia [1-3]. During early brain development, NSCs in the germinal region generate numerous progeny in a highly organized manner to construct the nervous system. Adult mammalian brains also harbour a population of 
adult NSCs that are primarily located in the subventricular zone of the lateral ventricle and the dentate gyrus of the hippocampus to maintain regional ongoing neurogenesis [4-7]. Advances in NSC biology have highlighted the promise of NSCs in stem cell-based therapies for neurological disorders [8-11]. Understanding molecular mechanisms regulating the behaviour of NSCs, including their proper expansion in vitro with multipotentiality but not tumorigenicity, is a critical step towards these goals.

As the defining hallmark of stem cells, self-renewal refers to the process by which stem cells expand to generate at least one of the two daughter cells with the same range of developmental potentials as its parental cell $[12,13]$. Stem cell self-renewal is critical for both embryonic development and adult homeostatic tissue maintenance. In the mammalian brain, NSCs are subject to tight and complex regulation in different regions and at different stages of development. The earliest neuroepithilial NSCs, for example, self-renew and expand rapidly to produce a vast number of progeny in order to meet the need of brain histogenesis. Whereas most adult stem cells in vivo usually reside in a micro-environment (niche) and remain relatively quiescent [14], they engage in active self-renewal upon injury signals or under certain physiologic conditions that demand rapid production of new progeny. Due to the complex nature of self-renewal in vivo, stem cells in culture provide a better-defined system to investigate how self-renewal is controlled by intrinsic and extrinsic mechanisms.

Emerging evidence suggests that self-renewal is regulated by diverse mechanisms in different stem cells $[13,15]$. In the case of NSCs, it has long been noted that cell expansion is promoted by the growth factor FGF-2, although litthe is known about the underlying cytoplasmic signalling mechanism [16-20]. NSCs isolated from different regions of the brain or different stages of development, grown as either "neurosphere" or adherent monolayer culture, all undergo robust proliferation when supplemented with FGF-2 in serum-free defined medium [21-25]. Selfrenewal entails not only proliferation but also maintenance of the stem cell state. Cellular sub-cloning experiments showed that the clonal progeny of NSCs still preserved multipotentiality after expansion by FGF-2 $[23,26]$, and in vitro expanded adult NSCs retained multipotentiality in vivo even after serial transplantation [27]. Genetic ablation of FGF-2 locus in mice resulted in severe defects in the maintenance of a slow-dividing stem cell pool, providing in vivo evidence that FGF-2 is necessary for normal NSC self-renewal [28]. Interestingly, FGF2 is present in normal adult NSC niches, can be induced by diverse types of pathological conditions, and is functionally capable of enhancing the inherently limited selfrenewal of endogenous NSCs after ischemic stroke [29-
35]. Under different biological contexts, FGF-2 may additionally act in coordination with many other types of extrinsic signalling molecules to exquisitely control adult NSC self-renewal in response to changes of cell physiological milieu, tissue homeostatic states and diverse environmental stimuli [5,10,36-41].

FGF-2 receptors (FGFRs) belong to the family of receptor tyrosine kinases $[42,43]$. The ligand binding, which is facilitated by heparin, leads to dimerization and autophosphorylation of FGFRs. Consequently, various phosphorylated tyrosine residues on the receptor serve as docking sites for adaptor or enzymatic proteins that link the receptor to downstream intracellular signalling pathways. Previous studies have implicated multiple pathways downstream of FGFRs, including the canonical MAPK (Extracellular signal-regulated kinase, Erk1/2) and phospholipase C (PLC) signalling $[42,44]$. However, it is unknown whether any of these pathways function in adult NSC self-renewal despite genetic evidence that has clearly implicated the role of FGFR1 in regulating adult NSC proliferation and neurogenesis $[32,45,46]$. Erk1/2 activation, for instance, has been shown to be important for myoblast proliferation, whereas its suppression promotes self-renewal of mouse embryonic stem cells $[47,48]$. These findings suggest that signalling pathways are largely conserved, yet their effects are context-dependent [42]. Thus, it is necessary to analyze the specific role of a given pathway in a particular cellular process.

In this study, we aim to gain molecular understanding on the role and mechanism of FGFR signalling in regulation of adult NSC self-renewal. Choosing the well-established rat hippocampal adult NSCs as our model system, we undertook multiple experimental strategies to assess whether specific FGFR signalling is sufficient to promote the self-renewal of adult NSCs, and further dissect out the functional requirement and cooperation of MAPK, PLC pathways in FGF-2-dependent self-renewal of adult NSCs.

\section{Results and discussion FGF-2 regulates the self-renewal of adult NSCs through promoting proliferation and inhibiting spontaneous differentiation}

When grown as monolayer cultures, adult rat hippocampal NSCs remain multipotent and their self-renewal is strictly dependent on FGF-2 (Additional file 1). Initially isolated and purified from adult rat hippocampus, these adult NSCs can be maintained for long-term in serum-free F12/N2 medium supplemented with $20 \mathrm{ng} / \mathrm{ml}$ FGF-2 $[22,24,25,49]$. They give rise to neurons, astrocytes and oligodendrocytes both in culture and after transplanted into the dentate gyrus of adult rats in vivo $[49,50]$. Clonalderived adult NSCs retain multi-lineage potentials, consistent with an FGF-2-dependent self-renewal of adult 

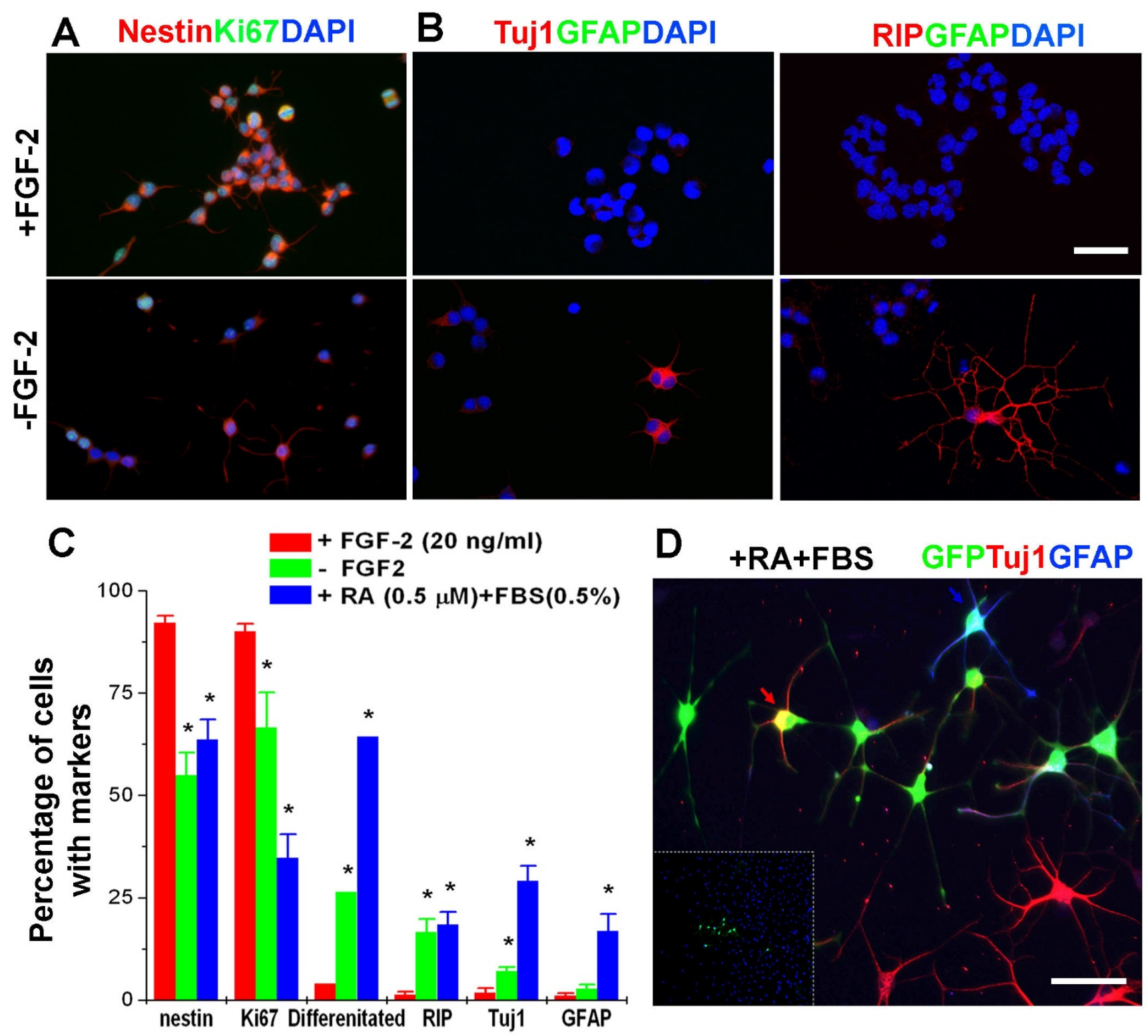

Figure I

FGF-2 regulates self-renewal of adult NSCs by promoting proliferation and inhibiting spontaneous differentiation. (A, B) Sample immunostaining images of adult NSC culture with or without treatment of exogenous FGF-2 (20 ng/ml). Nestin is a neural precursor cell marker; Ki67 is a cell proliferation marker; Tuj I is a neuronal marker; RIP is an oligodendrocyte marker; GFAP is an astrocyte marker. Scale bar: $20 \mu \mathrm{m}$. (C) Quantification of the percentage of cells with characteristic markers in the presence or absence of FGF-2, or after treatment of RA $(0.5 \mu \mathrm{M})$ and FBS $(0.5 \%)$. Values represent mean \pm SEM. ( $\mathrm{n}=6$; *: $\mathrm{P}<0.0 \mathrm{I}$, Student's t-test). (D) Multi-lineage differentiation potentials of adult NSCs after long-term culture in the presence of FGF-2. EGFP was used to label a single cell and allowed to expand in the presence of FGF-2 (20 ng/ml) and then induced to differentiate into Tuj ${ }^{+}$neurons (red) and GFAP ${ }^{+}$glia (blue) with RA (0.5 $\mu$ M) and FBS (0.5\%) for 6 days. Scale bar: $20 \mu \mathrm{m}$. 
NSCs (Figure 1). To evaluate the effect of FGF-2 on adult NSC self-renewal, we assessed several integral aspects of stem cell self-renewal: proliferation, anti-differentiation, and maintenance of multipotentiality.

In the presence of FGF-2, the adult NSC culture comprised mostly Nestin ${ }^{+}$(a neural progenitor maker) and Ki67+ (a proliferation marker) population (Figure 1A). Differentiation markers Tuj1 (neuronal), GFAP (astroglial), and RIP (oligodendroglial) were rarely detected (Figure 1B). By contrast, withdrawal of FGF-2 led to significant cell cycle arrest and spontaneous differentiation within 4 days, as shown by a significant decrease in the percentage of Ki67+ and Nestin ${ }^{+}$cells and an increase of spontaneous neuronal and oligodendroglial differentiation (Figure 1B, C). Overall, the percentages of apoptotic cells were not significantly altered with or without FGF-2 under these culture conditions. When the multipotentiality of adult NSCs was examined at different passages (passage 15, 25, 35), the culture consistently generated both neurons and glia. Furthermore, EGFP-labelled clonal-derived adult NSCs gave rise to both Tuj $1^{+}$neurons and GFAP+ astrocytes (Figure 1D). These results suggest that FGF-2 promotes selfrenewal of NSCs by stimulating proliferation, inhibiting spontaneous differentiation, and maintaining multipotentiality.

\section{A chimeric receptor recapitulates effects of FGF-2 and implicates ErkI/2 and PLC $\gamma /$ signalling in adult NSC self- renewal}

How does FGF-2 exert such wide-ranging effects on adult NSCs? Among the four members of FGFRs, FGFR1 was highly expressed in adult NSCs (Figure 2A). These adult NSCs exhibited little endogenous NGF receptor TrkA transcript during proliferation (Figure 2A). To test whether FGFR1 activation is sufficient to promote self-renewal, we derived an adult NSC line harbouring a chimeric receptor with the extracellular domain of NGF receptor TrkA and the intracellular domain of FGFR1 (TF1 line; Figure 2A). In the chimeric NSC line, NGF was sufficient to activate FGFR1 signalling and mimic effects of FGF-2 in promoting long-term proliferation and inhibiting differentiation of adult NSCs (Figure 2B, C). Importantly, the chimeric TF1 NSC line remained to be responsive to FGF-2, and multipotent after long-term culture in the present of NGF (Figure 2B, C, E), suggesting that FGFR1 signalling is sufficient to promote proliferation and maintain multipotentiality of adult NSCs.

By expressing a chimeric TrkA-FGFR receptor, we used NGF as a surrogate ligand to activate FGFR1 and examined the influence of specific mutations from the intracellular domain of FGFR1 on adult NSC self-renewal. We established lines of adult NSCs with a series of chimeric receptor constructs, including TrkA-FGFR1 (TF1), TF1L422A,
TF1Y463F, TF1Y653/4F, and TF1Y766F (Figure 2A). L422 is a critical leucine amino acid residue site for FRS2 binding, and its mutation leads to loss of downstream signalling through the FRS2-Ras-MAPK cascade [51]. Y653/4F (tyrosine to phenylalanine) is an FGFR1 kinase enzymatic inactive mutation, and Y463F and Y766F disrupt substrate actions of the tyrosine kinase Crk and a member of the PLC family, PLC $\gamma 1$, respectively [44,52]. In NSC proliferation assay, NGF recapitulated the effect of FGF-2 for the TF1 line, whereas NGF failed to stimulate the proliferation of the TF1Y653/4F kinase dead mutant line (Figure 2D). In contrast, NGF-induced expansion of TF1L442A, TF1Y766F lines were significantly decreased compared to the TF1 line. Importantly, all these adult NSC lines retained normal self-renewal in response to FGF-2 (Figure 2D). Taken together, these results indicate that L442 and Y766 linked downstream Ras-MAPK and PLC 1 activation are likely essential for maintaining adult NSCs, through direct regulation of NSC proliferation and/or maintenance of progenitor characteristics.

Using phospho-specific antibodies against Erk1/2 and PLC $\gamma 1$, western blot analysis showed that FGF-2 induced prominent Erk1/2 and PLC $\gamma 1$ activation (Figure 3A). While Erk1/2 phosphorylation persisted into 24 hours after the addition of FGF-2, PLC $\gamma 1$ tyrosine phosphorylation appeared to be transient in nature. The dependence of Erk1/2 and PLC $\gamma 1$ activation on L442 and Y766 residues was confirmed in chimeric NSC lines with respective signalling deficiencies (Figure 3C to 3E). Collectively, these results suggest that two key amino acid residues in the intracellular domain of FGFR1 are important for adult NSC self-renewal and mediate the effects of FGF-2 through ERK and PLC $\gamma 1$ signal transduction pathways.

\section{Activation of ErkI/2 is both required and sufficient for the proliferation of adult NSCs}

To directly examine the specific role of Erk1/2 activation in adult NSC self-renewal, we treated adult NSC cultures with U0126, a selective and potent inhibitor for the Erk1/ 2 kinase MEK1/2 [53]. As shown by western blot analysis (Figure 4A), FGF-2-stimulated Erk1/2 activation was inhibited by $U 0126$ in a dose-dependent manner. In adult NSC culture treated with $2.5 \mu \mathrm{M} U 0126$, the percentage of Ki67 or Nestin positive cells was significantly lower than the untreated culture (Figure 4B). In contrast, U0124, the inactive analogue of U0126, elicited no significant effects. When subjected to clonal analysis assay in measuring selfrenewal expansion at the single cell level (Additional file 2), U0126 also suppressed FGF-2-induced clonal expansion of EGFP-labelled NSCs in a dose-dependent manner (Figure 4C, D).

To further examine the role of Erk1/2 activation in adult NSC proliferation, we engineered retroviruses to over- 

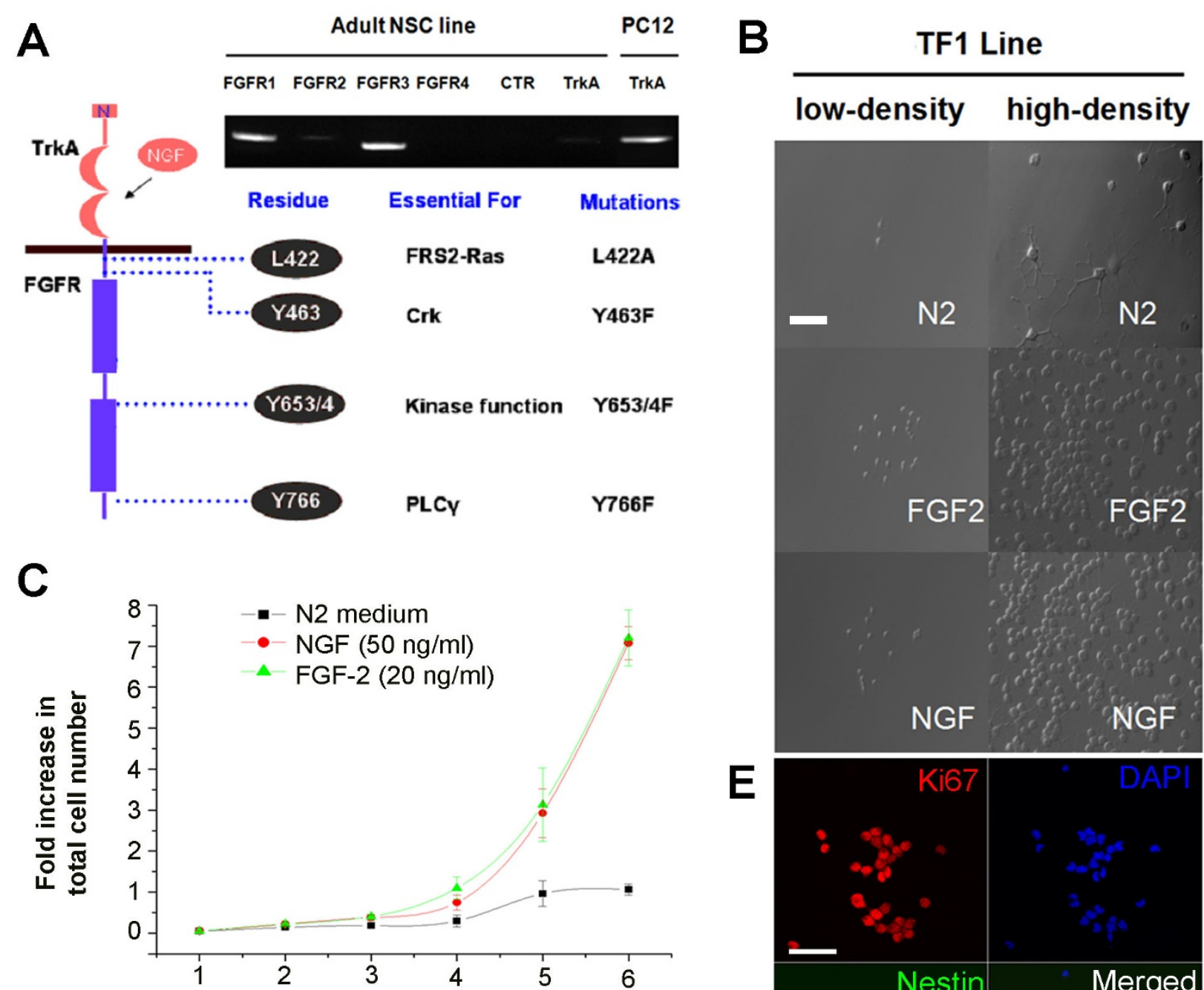

Time in culture (days)
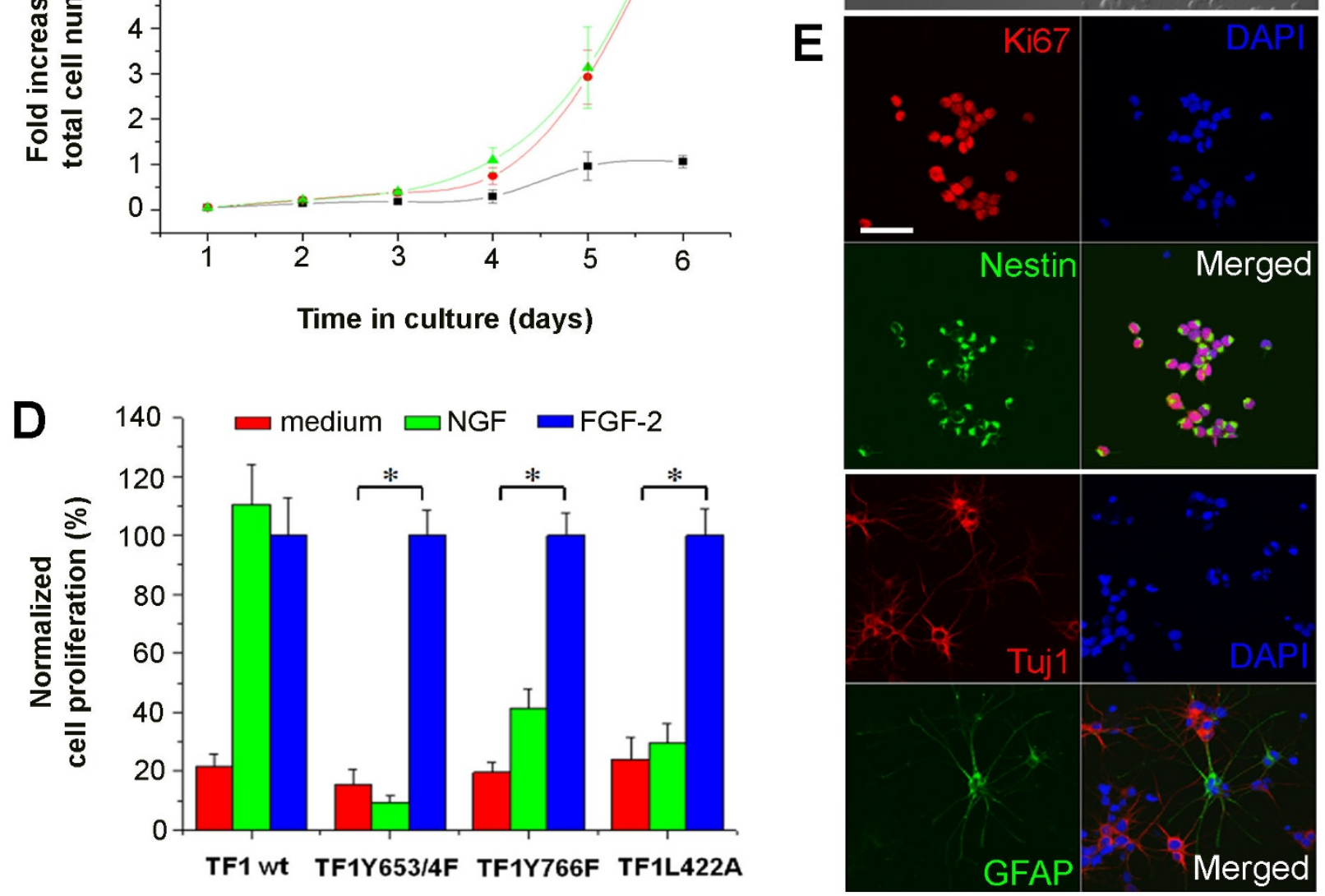

Figure 2 (see legend on next page) 
Figure 2 (see previous page)

A chimeric receptor recapitulates effects of FGF-2 and implicates Erk I/2 and PLC $\gamma$ I signalling in adult NSC self-renewal. (A) A schematic diagram illustrating the chimeric receptor and the amino acid residues within the FGFRI intracellular domain that are linked to various downstream signalling pathways. Shown on the top is the RT-PCR analysis of the expression of endogenous TrkA and FGFRs under the proliferating condition in the presence of FGF-2. (B) A bright-field view (low and high density) of NSC lines with the TFI chimeric receptor grown in the presence of FGF-2 (20 ng/ml) or the surrogate ligand NGF $(50 \mathrm{ng} / \mathrm{ml})$. Scale bar: $20 \mu \mathrm{m}$. (C) Growth curves of the NSC lines with TFI chimeric receptors in the absence, and presence of FGF-2 $(20 \mathrm{ng} / \mathrm{ml})$ or the surrogate ligand NGF $(50 \mathrm{ng} / \mathrm{ml})$. Values represent mean \pm SEM. ( $\mathrm{n}=3)$. (D) Quantification of NSC numbers of various chimeric receptor lines cultured in the medium alone, or with supplementation of FGF-2 $(20 \mathrm{ng} / \mathrm{ml})$ or NGF $(50 \mathrm{ng} / \mathrm{ml})$. For each line, the total NSC numbers were normalized to those cultures in the presence of FGF-2 (20 ng/ml). Values represent mean \pm SEM. ( $\mathrm{n}=3$; *: $\mathrm{P}<0.0 \mathrm{l}$, Student's t-test). (E) Normal NSC characteristics and multipotentiality of the TFI chimeric NSC line maintained by NGF. Shown on the top are sample images of immunostaining of proliferating NSCs with Ki67 (red) and Nestin (green). Shown on the bottom are sample images of immunostaining with Tuj I (red) or GFAP (green) of cultures at 6 days after the treatment of RA $(0.5 \mu M)$ and FBS (0.5\%). Scale bar: $20 \mu \mathrm{m}$.

express the dominant negative (DN), wild-type (WT) and constitutively active (CA) mutants of MEK1 in adult NSCs (Figure 4E, F). These mutants have been widely used to manipulate cellular Erk1/2 activity [54,55]. Bicistronic expression of EGFP was used to monitor transduced cells with infection efficiency over 95\%. Western blot analysis using phosph-Erk1/2 antibodies confirmed that MEK1DN NSCs effectively attenuated Erk1/2 activation, and MEK1-CA rendered Erk1/2 constitutively active in adult NSC culture (Figure 4E). In clonal analysis assay, MEK1DN NSCs produced significantly reduced clone sizes in the FGF-2 treated condition, whereas MEK1-CA NSCs yielded significantly increased clone sizes even in the absence of FGF-2 (Figure 4F). Collectively, these data suggest that Erk1/2 activation is both required and sufficient for FGF-2-dependent proliferation of adult NSC.

\section{Activation of Erk I/2 blocks both spontaneous and induced differentiation of adult NSCs}

Spontaneous differentiation of some adult NSCs was also observed after U0126 treatment or MEK1-DN expression. Next, we examined the role of Erk1/2 pathway in the antineuronal differentiation effect of FGF-2 on adult NSCs in detail. Spontaneous NSC differentiation occurred at a very low basal level in the presence of FGF-2 (Figure 5A). Treatment of U0126 $(2.5 \mu \mathrm{M})$, but not U0124, led to significant spontaneous differentiation of adult NSCs into RIP+ oligodendrocytes and Tuj $1^{+}$neurons (Figure 5A). Similarly, the NSC line expressing MEK1-DN exhibited a higher spontaneous differentiation rate than both MEK1WT and MEK1-CA lines. In standard differentiation condition with the treatment of retinoic acid (RA; $0.5 \mu \mathrm{M}$ ) and fetal bovine serum (FBS; 0.5\%) for 6 days [24,56], adult NSC lines expressing MEK1-CA generated a significantly lower percentage of $\mathrm{RIP}^{+}$oligodendrocytes and Tuj $1^{+}$neurons (Figure 5B). Meanwhile, most cells from MEK1-CA NSC lines remained in cell cycle as indicated by the significantly higher percentage of $\mathrm{Ki}^{+} 7^{+}$cells (Figure 5B). We further explored these changes in neuronal differentiation by performing western blot analysis. Tuj1 was up-regulated in the absence of FGF-2 and reached a higher level under differentiation conditions (Figure 5C). Such increase was accelerated in the MEK1-DN NSC lines and abrogated in the MEK1-CA NSC lines.

Considering the phenotype of MEK1 NSC lines, we also tested whether expression and regulation of key genes involved in proliferation and differentiation were affected in MEK1 NSC lines. Indeed, NeuroD1, an essential transcription factor for neuronal differentiation, was strongly down-regulated in the MEK1-CA NSC line compared to the MEK1-DN and WT NSC lines (Figure 5D). Interestingly, CyclinD2, one of the key genes for cell cycle progression showed a reverse expression pattern as NeuroD1. It has been shown that FGF and Shh control CyclinD2 and CyclinD1 expression to maintain the cycling and undifferentiated progenitor states at different brain regions with NSCs, respectively [57]. While it is likely that proliferation and anti-differentiation are coupled events, Erk1/2 may also promote cell cycle progression and inhibit precocious differentiation programs by independent mechanisms. One of the prominent targets is Notch signalling, which has been shown to inhibit neuronal differentiation from multiple types of NSCs and its constitutive activation led to astrocyte differentiation [58]. In adult NSCs, we detected abundant expression of a Notch ligand Jagged-1 in the MEK1-CA, but not in MEK1-DN or WT NSCs, suggesting that Jagged-1 and Notch signalling may mediate the anti-differentiation effects of MEK1 (Figure 5D). Taken together, these results indicate that the MAPK-ERK pathway of FGFR1 signalling prevents both spontaneous and induced neuronal and oligodendroglial differentiation, possibly through regulation of key genes including NeuroD1 and CyclinD2. 
A

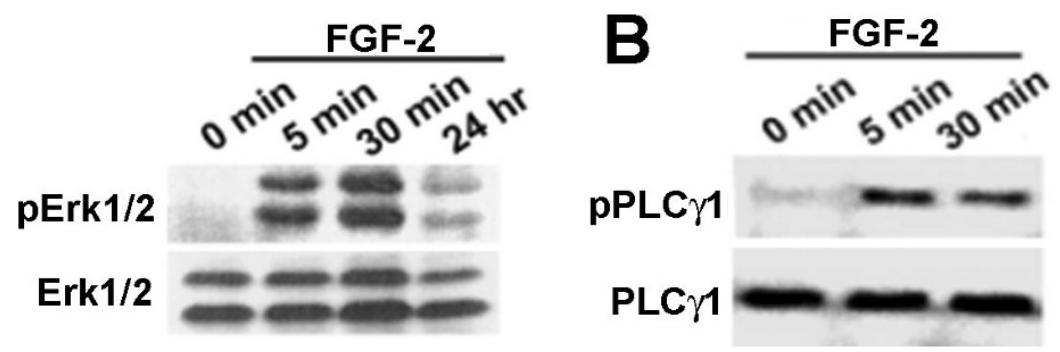

C

\begin{tabular}{|c|c|c|c|c|c|c|}
\hline \multirow[b]{2}{*}{ NGF $(50 \mathrm{ng} / \mathrm{ml})$} & \multicolumn{3}{|c|}{ TF1 } & \multicolumn{3}{|c|}{ WT } \\
\hline & - & + & - & - & + & - \\
\hline GF-2 (20 ng/ml) & + & - & - & + & - & - \\
\hline pErk1/2 & $=$ & $=$ & - & - & 5 & and \\
\hline Erk1/2 & & - & & $=$ & $=$ & $=$ \\
\hline
\end{tabular}

D

TF1L422A

FGF-2 (20 ng/ml)

NGF (50 ng/ml)

pErk1/2

Erk1/2

$\begin{array}{ll}\text { TF1L422A } \\ ++\quad- & - \\ -\quad+ & -\end{array}$

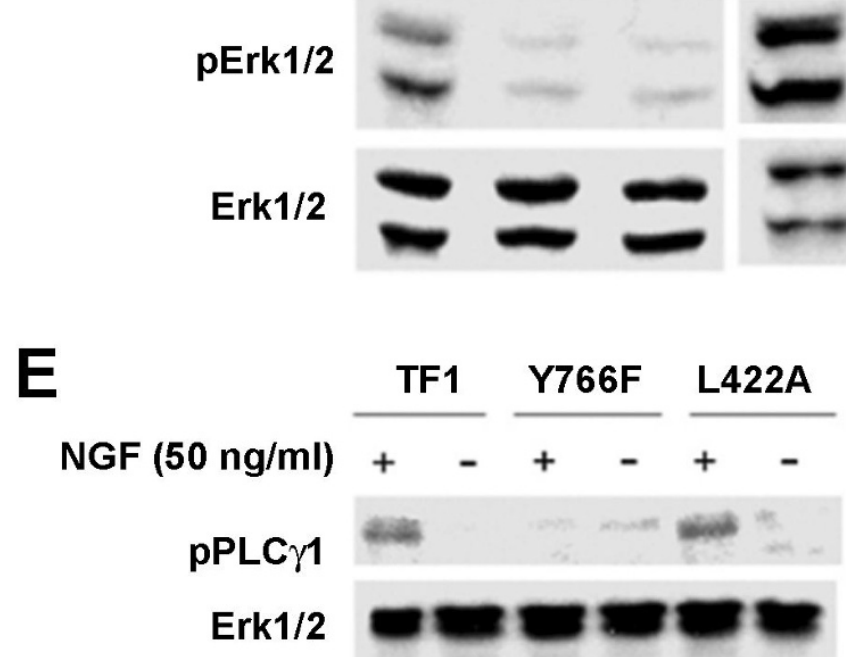

Figure 3

Specific activation of signal transduction pathways in chimeric receptor lines with various mutations of several key amino acid residues of FGFRI. (A-B) Western blot analysis of ErkI/2 and PLC $\gamma$ I phosphorylation in normal adult NSCs in response to FGF-2 (20 ng/ml). (C-D) Western blot analysis of NGF-induced Erkl/2 phosphorylation in the TFI line and in the mutant TFIL422A or TFIY766F chimeric lines. (E) Western blot analysis of NGF-induced PLC $\gamma$ I phosphorylation in the mutant TFIL422A or TFIY766F chimeric lines. 
A

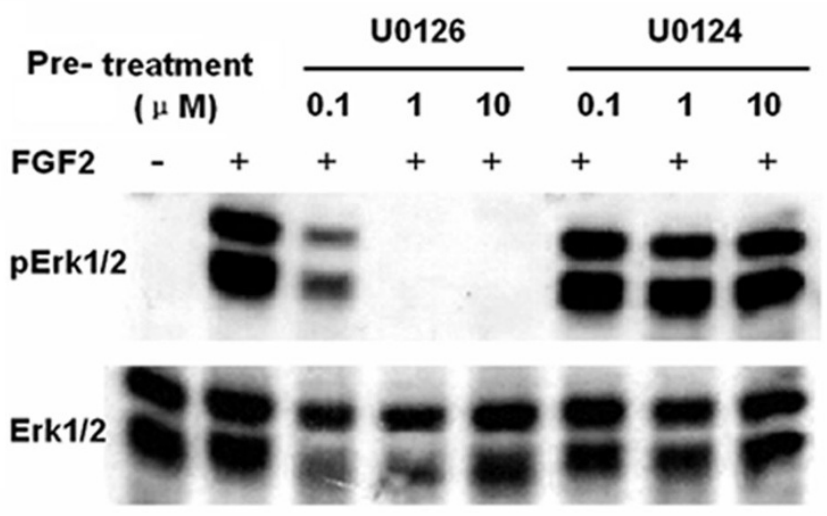

C

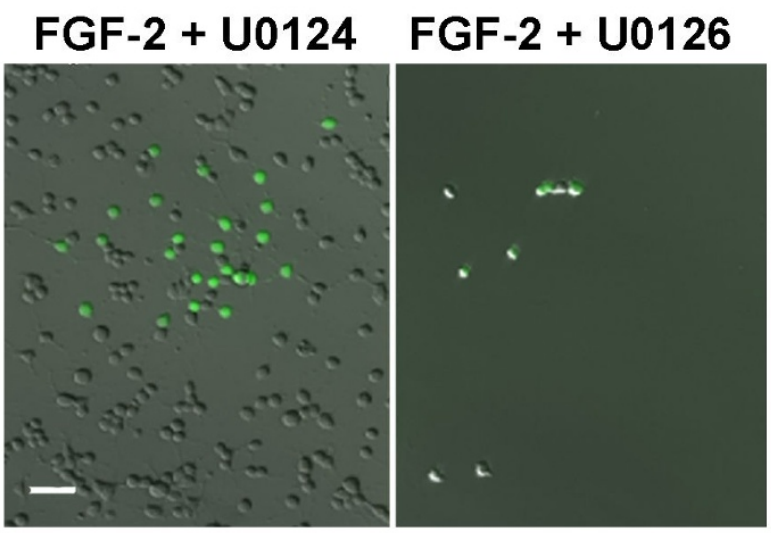

E

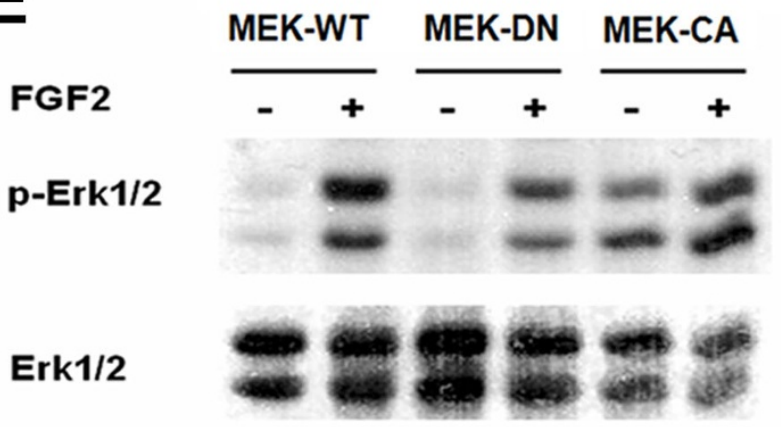

B FGF-2 U0126 U0124

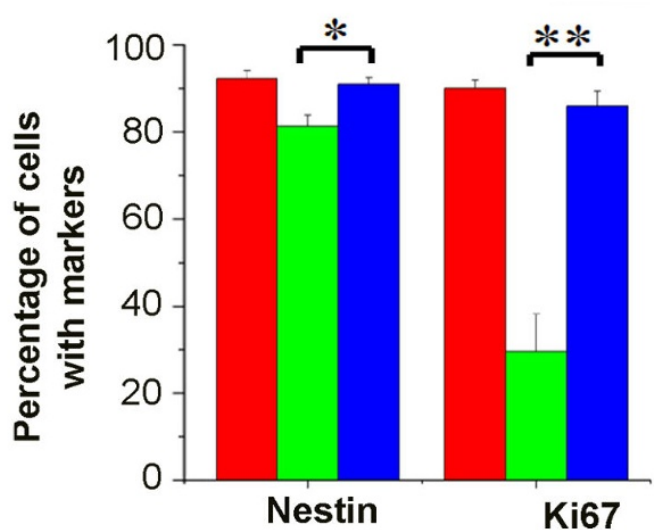

D

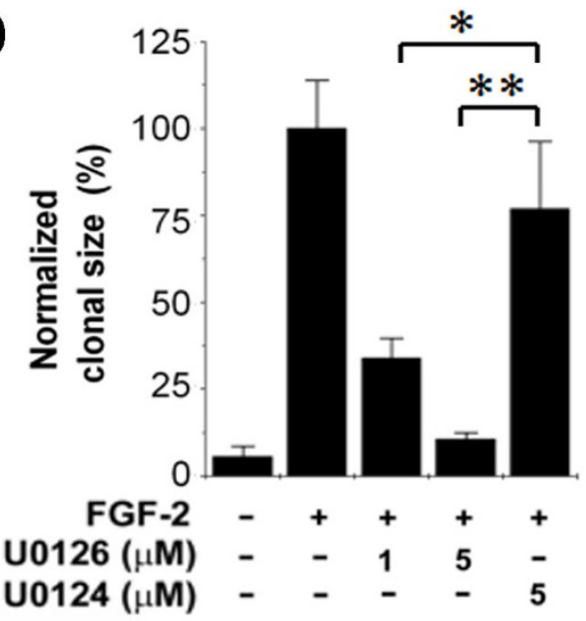

$\mathbf{F}$

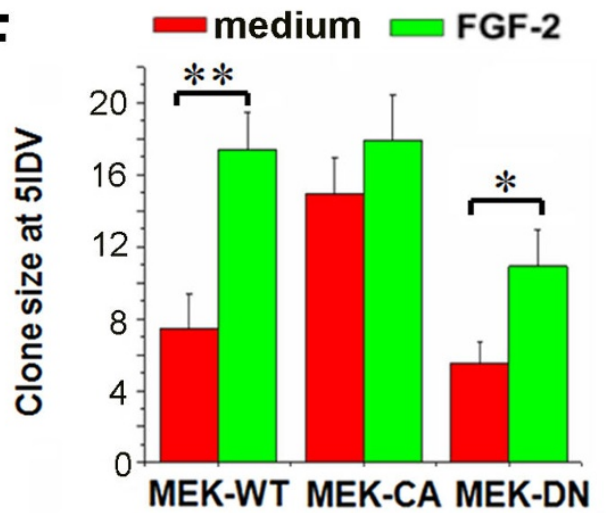

Figure 4

Erk I/2 Activation is both required and sufficient for adult NSC proliferation. (A) Western blot analysis of Erk I/2 inhibition in normal adult NSCs with the treatment of U0I26 or U0I24 at different concentrations. (B) Quantification of the cellular composition of adult NSC culture in the presence or absence of U0I26, or its inactive analog U0I 24 (2.5 $\mu$ M). Values represent mean \pm SEM. $(n=6$; *: $P<0.0$ I, Student's t-test). (C) Sample images of clonal analysis of adult NSCs with MEKI inhibition. Scale bar: $20 \mu \mathrm{m}$. (D) Summary of clonal analysis of adult NSCs in the presence of U0I26 or U0I24. (E) Western blot analysis of ErkI/2 activation in MEKI-WT, DN or CA lines. (F) Summary of clonal analysis assay for adult NSCs expressing MEKI-DN, WT or CA. Values represent mean \pm SEM. $(n=3 ; *: P<0.01$, Student's t-test). 

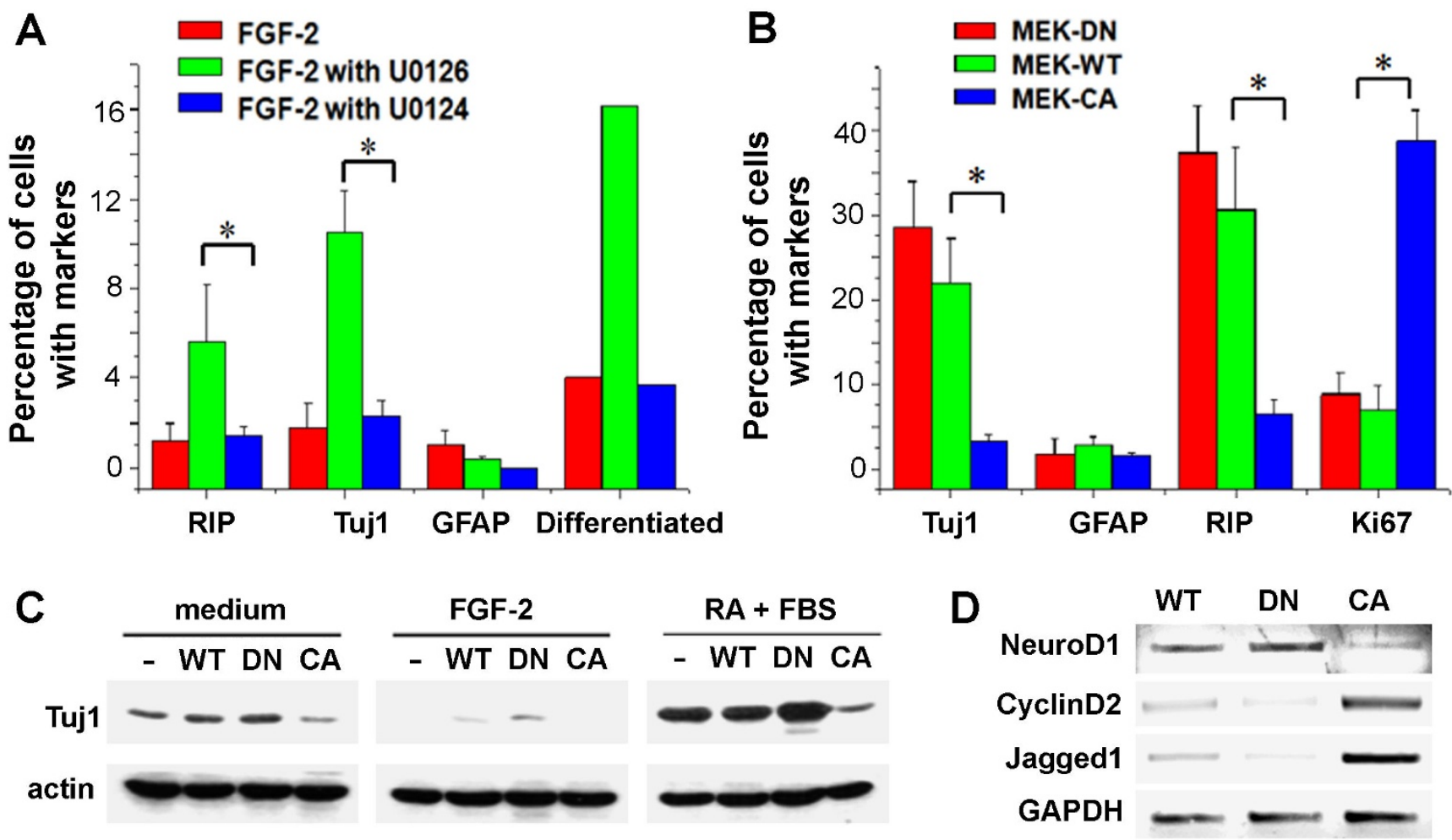

\section{Figure 5}

Erk I/2 Activation blocks both spontaneous and induced differentiation. (A) Cell number quantification for each differentiation marker (Tuj I, GFAP or RIP) in proliferating adult NSC culture in the presence of FGF-2 (20 ng/ml) and with U0I 26 or U0I24 $(2.5 \mu \mathrm{M})(\mathrm{n}=6$; *: P < 0.0I, Student's t-test). (B) Cell number quantification for each differentiation marker (Tuj I, GFAP or RIP) in adult NSCs expressing MEKI-WT, DN, or CA at 6 days after the induction of differentiation with RA (0.5 $\mu \mathrm{M})$ and FBS (0.5\%) $(n=3$; *: $\mathrm{P}<0.0$ I, Student's t-test). (C) Western blot analysis of neuronal marker Tuj I expression in adult NSCs expressing MEKI-WT, DN, or CA under the medium only, FGF-2 supplemented and normal differentiation with RA (0.5 $\mu \mathrm{M})$ and FBS $(0.5 \%)$ conditions. (D) Semi-quantitative RT-PCR analysis on the induction of NeuroD, CyclinD2 and Jag I genes in adult NSCs expressing MEKI-WT, DN, or CA under the differentiation condition.

\section{PLC $\gamma$ I maintains neuronal and oligodendroglial differentiation potentials of adult NSCs}

In parallel with the MAPK pathway, we also examined how PLC $\gamma 1$ might participate in regulating adult NSC selfrenewal. To directly ascertain the function of PLC $\gamma 1$, we designed and screened a number of small hairpin RNAs (shRNA) to knockdown endogenous PLC $\gamma 1$ expression in adult NSCs (Figure 6A). Retroviruses carrying the shRNAs along with a visualizing marker ZsGreen were used to infect adult NSCs. Both western blot analysis and immunostaining confirmed the knockdown efficacy of one shRNA from the screen (Figure 6A-B). This shRNA targets the 3'UTR region to allow rescue experiments with the exogenous full-length cDNA of PLC $\gamma 1$.

Under normal proliferation conditions, PLC $\gamma 1$-depleted cells exhibited decreased number of GFAP negative and Nestin positive cells, consistent with results from the mutant chimeric receptor NSC line TF1Y766F (Figure
2D). We next assessed the differentiation profile of adult NSCs infected with PLC $\gamma 1$-shRNA and control shRNA viruses. Surprisingly, in the standard differentiation condition with $0.5 \mu \mathrm{M}$ RA and $0.5 \%$ FBS for 6 days, the majority of the progeny of PLC $\gamma 1$-shRNA cells consisted of $\mathrm{GFAP}^{+}$astrocytes, instead of a mixed population of neurons and glia as seen in control (Figure 6D). Cell death rates were not significantly altered in these conditions. A large fraction of PLC $\gamma 1$-depleted cells remained to be undifferentiated even with RA and FBS (Figure 6D), in sharp contrast to adult NSCs with Erk1/2 inhibition, which led to reduced proliferation and elevated neuronal differentiation of adult NSCs (Figure 5). Even in the normal proliferation condition, the number of GFAP positive and Nestin negative cells slightly increased among PLC $\gamma 1$ depleted cells. Results from immunostaining-based quantitative cell counting were further supported by western blot analysis (Figure 6C and Additional file 3). The amounts of neuronal and oligodendroglial differentiation 
A

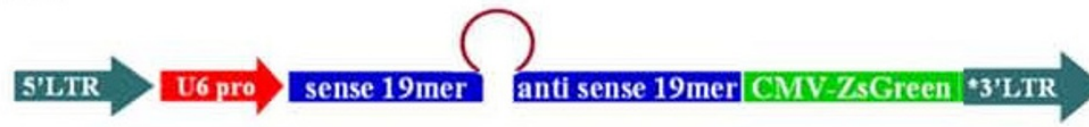

PLC- 11

Actin

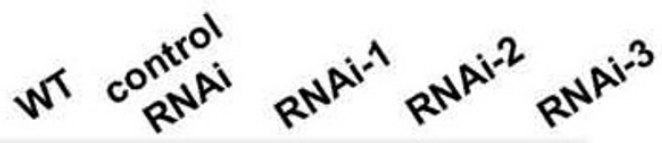

C

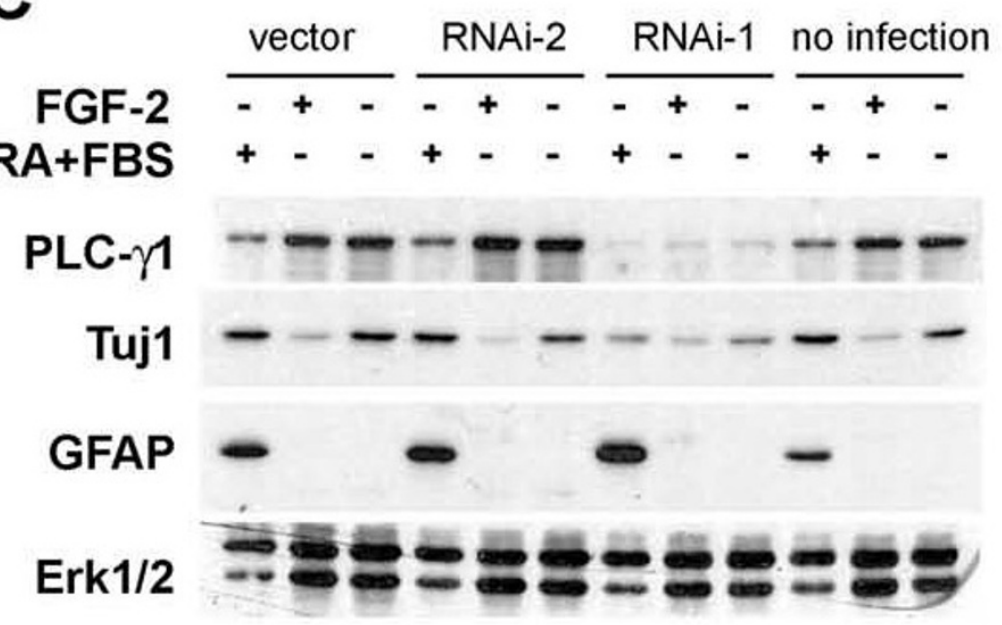

E

$\begin{array}{lllll}\text { Control RNAi } & + & - & + & - \\ \text { PLCY1 RNAi } & - & + & - & + \\ \text { PLCY1 cDNA } & - & - & + & +\end{array}$

PLC- $\gamma 1$

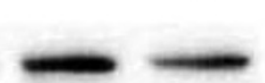

Tuj1

Actin
B

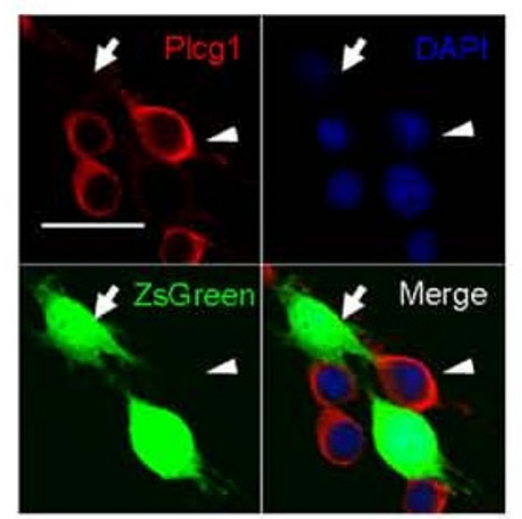

D

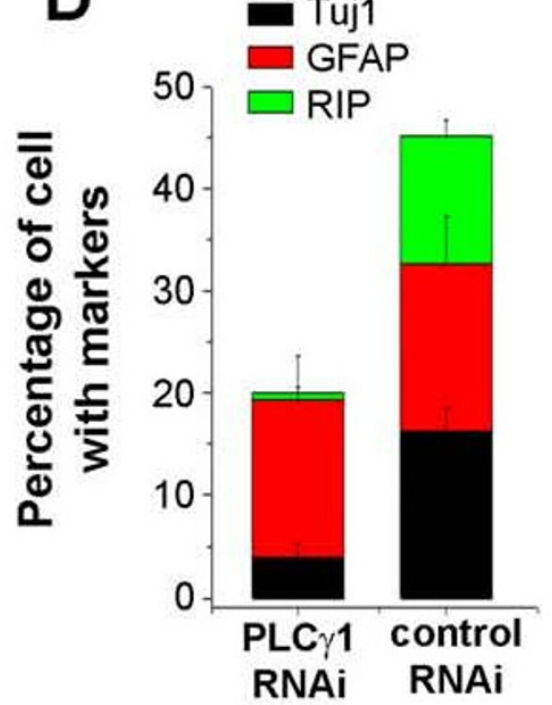

F

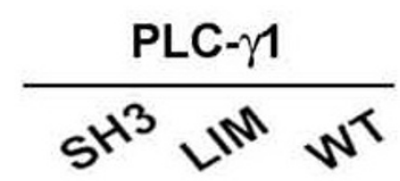

Tuj1

Actin

FGF-2

Tuj1

Actin
$R A+F B S$

Figure 6 (see legend on next page) 
Figure 6 (see previous page)

Impairment of neuronal and oligodendrocyte differentiation in PLC $\gamma$ I-depleted adult NSCs. (A) A schematic diagram illustrating the retroviral shRNA construct and western blot analysis on the efficacy of knockdown by shRNAs against endogenous PLC $\gamma \mathrm{I}$ in adult NSCs. (B) Immunostaining of endogenous PLC $\gamma$ I in NSCs infected with shRNA-il. Scale bar: 20 $\mu \mathrm{m}$. (C) Western blot analysis of neuronal differentiation marker Tuj I and glial marker GFAP in PLC $\gamma$-depleted NSCs in the presence or absence of FGF-2, or after induction of differentiation with RA (0.5 $\mu \mathrm{M})$ and FBS (0.5\%) for 6 days. (D) Quantification of various cell types in PLC $\gamma$ l-depleted NSCs after induction of differentiation with RA (0.5 $\mu$ M) and FBS (0.5\%) for 6 days. Values represent mean \pm SEM. ( $n=4$; *: $P<0.0$ I, Student's t-test). (E) Rescue of neuronal differentiation defects of endogenous PLC $\gamma \mathrm{l}$-depleted adult NSCs by exogenous expression of PLC $\gamma$ I cDNA plasmid. (F) Western blot analysis of neuronal differentiation marker Tuj I after differentiation of adult NSCs expressing WT and two different dominant negative mutants of PLC $\gamma$ I (LIM: lipase inactive mutant, SH3: SH3 domain deletion mutant).

markers Tuj1 and CNPase, but not astroglial marker GFAP, were significantly less abundant in PLC 1 1-shRNA cells than the normal, vector transduced, or control shRNA virus transduced adult NSCs after induction of differentiation. Importantly, introducing WT PLC $\gamma 1$ cDNA back into the PLC $\gamma 1$-shRNA cells rescued the impaired neuronal differentiation capacity of cells depleted with PLC 1 , excluding potential off-target effects of this particular shRNA (Figure 6E). Furthermore, adult NSCs expressing the lipase-inactive DN form of PLC 1 [59] exhibited similar deficits of neuronal differentiation (Figure 6F). These experiments demonstrate that knockdown of PLC $\gamma 1$ leads to largely exclusive commitment of adult NSC towards astroglial fates, suggesting an essential role of PLC 1 to maintain the full developmental potential of adult NSCs for proper neuronal and oligodendroglial differentiation.

Intriguingly, the phenotype of PLC $\gamma 1$-depleted cells resembles glioblastoma, a type of brain tumor cells that also exhibit impaired capacity for neuronal and oligodendroglial differentiation [60,61]. Accumulating evidence also suggests that adult NSCs in vivo express GFAP, an astrocytic marker, and glioblastoma may originate from adult NSCs [60,61]. In addition to the impaired neuronal and oligodendroglial differentiation, PLC $\gamma 1$-shRNA cells exhibited enhanced GFAP expression in the presence of FGF-2 (Figure 6C). It is thus plausible that PLC $\gamma 1$ normally regulates the transition of multipotent NSCs into astrocyte versus other fates, and its depletion may predispose NSCs to glial differentiation thus compromising multipotentiality. Consistent with this notion, PLC $\gamma 1$ is abundantly expressed by embryonic radial glia during fetal brain development, and its overall expression is inversely correlated with GFAP expression from the embryonic stage E14 to adulthood [62].

Our results support a model that FGF-2 induced Erk1/2 activation promotes the proliferation and blocks the spontaneous neuronal and oligodendrocyte differentiation of adult NSCs, while in parallel FGF-2-induced activation of PLC 1 pathway maintains the full differentiation capacity of NSCs into neuronal and oligodendroglial lineages by preventing excess astroglial commitment of adult NSCs (Additional file 4). Other pathways downstream of FGF-2 or alternative signal transduction machineries, such as EGF, BMP, WNT, SHH, and cytokine signalling molecules, may also interact with the pathways studied in our work, and converge on the regulation of adult NSC self-renewal in a context-specific and coordinated manner $[36,38,40,46,63-70]$. Given that FGF-2 is normally expressed in adult NSC niches, induced by diverse injuries such as ischemic stroke, and promotes the mobilization and self-renewal of adult NSCs in certain physiological and pathologic conditions [29-35], it will be of interest in the future to investigate the involvement and functionality of these FGF-2 dependent intracellular signalling pathways in regulating adult NSC self-renewal in vivo in normal and disease contexts.

\section{Conclusion}

Understanding molecular mechanisms of stem cell behaviour regulated by extrinsic factors is an important step towards therapeutic application of NSCs for neurodegenerative diseases. Here we identified two key intracellular signalling pathways that dictate distinct aspects of adult NSC self-renewal in response to FGF-2. Erk1/2 pathway mediates both the proliferation and anti-neuronal differentiation effects of FGF-2, whereas PLC $\gamma 1$ maintains adult NSC characteristics and developmental potentials of adult NSCs for neuronal and oligodendroglial differentiation. Coordination of these two pathways ensures that adult NSC self-renewal is under the stringent control of growth factor signalling, and to potentially prevent adult NSCs from transforming into cancerous stem cells such as glioblastoma, and losing precocious multipotentiality.

FGF-2 signaling is essential for self-renewal of adult neural stem cells from multiple mammalian species, including humans (Additional file 1). Our findings provide mechanistic insights into the molecular and cellular machinery regulating adult NSC self-renewal. Molecular genetic dissection of the FGFR1 pathway in this study also suggests novel biomarkers and interventions for monitoring and 
preserving desired NSC states, and thus have clear implications for potential uses of adult NSCs expanded in vitro in therapeutic applications.

\section{Methods}

\section{Isolation, Culturing and Differentiation of Adult NSCs}

The adult NSC line was initially established from primary adult rat NSCs $[22,24]$. These adult NSCs were isolated from hippocampi of adult (3-month-old) male Fischer 344 rats. Briefly, hippocampi were dissected and transferred to PBS medium containing penicillin and streptomycin. Tissue was washed, minced, and enzymatically digested for about $30 \mathrm{~min}$ in a mixture of $0.1 \%$ neural protease, $0.01 \%$ papain and $0.01 \%$ DNAse I. Tissue was then mechanically dissociated and cells were washed, centrifuged, and resuspended in DMEM containing 10\% FBS. Equal volume of Percoll was added, and cells were centrifuged at 12,700 RPM for $30 \mathrm{~min}$. The middle layer of the gradient were removed and washed 3 times with PBS. Cells were then resuspended and counted before plated on laminin-coated flasks in DEME/F12 medium containing N2 supplement, L-glutamine (2 mM) and FGF-2 (20 $\mathrm{ng} / \mathrm{ml}$ ) as described $[22,24]$. Cells were passaged for expansion when reaching $70 \%$ confluence or seeded at clonal density for experiments. For differentiation studies, fresh RA $(0.5 \mu \mathrm{M})$ and FBS $(0.5 \%)$ were added to FGF-2 free culture for six days and the medium was changed every 3 days with fresh RA and FBS.

\section{Constructs and molecular biology}

The original chimeric TF1 constructs [71] were sub-cloned into the retroviral vector pBMN-IRES-EGFP upstream of IRES-EGFP. Mutagenesis was performed by QuickChange (Stratagene) and confirmed by sequencing. The vector pSilencer-RetroQ (Clontech) was used to amplify the fragment containing the U6 promoter by a universal sense primer and an shRNA-containing antisense primer. PCR products were cloned into pSilencer-RetroQ to generate retroviral vectors. The primer sequence for PLC $\gamma 1$ shRNA was as follows: PLC $\gamma 1$ : 5'-CTAGAATTCACGCGTAAAAAA GAAACAACCGGCTCTTCGTCCAAGCTTCGACGAAGAG CCGGTTGTTTCGGATCCTCGTCCTTTCCACA. Scrambled sequences were used as controls.

\section{Virus Production and Transduction}

Phoenix Eco-packaging cell line or 293-gp cells (Clontech) were transfected with retroviral vectors pseudotyped with VSVG by calcium phosphate methods as previously described $[72,73]$. Supernatant was collected and subject to ultra-centrifugation ( $25 \mathrm{k} \mathrm{rpm}, 90 \mathrm{~min})$. Titer of virus was determined in NIH3T3 cells and aliquots were frozen at $-80^{\circ} \mathrm{C}$. Transduction was performed overnight with 2 $\mu \mathrm{g} / \mathrm{ml}$ polybrene in a minimum volume of medium as previously described [74].

\section{Immunocytochemistry and in Vitro Quantification}

Cells were fixed with $4 \%$ paraformaldehyde, followed by immunocytochemical staining as described [22,24,56]. The following primary antibodies were used: rabbit antiTuj1 (1:7500; Covance), mouse anti-RIP (1:50; Hybridoma Bank); guinea pig anti-glial fibrillary acidic protein (GFAP; 1:2,500; Advanced Immunochemical), mouse anti-PLC $\gamma 1$ (1:1000; Upstate). After incubation with secondary antibodies (1:250; Jackson Immunoresearch) for $90 \mathrm{~min}$ at room temperature, cultures were rinsed, stained with 4',6-diamidino-2-phenylindole (DAPI), rinsed, mounted and stored at $4{ }^{\circ} \mathrm{C}$. Images were taken with fluorescence confocal microscopy system (Zeiss LSM510). All experiments were independently replicated at least three times.

\section{Clonal analysis assay}

Retrovirus transduced NSCs were mixed with WT NSCs at a clonal ratio (generally 1:40) and assayed for clone size and clonal composition in various conditions. For each chimeric receptor, infected culture was grown in the presence of FGF-2 $(20 \mathrm{ng} / \mathrm{ml})$, NGF $(50 \mathrm{ng} / \mathrm{ml})$, or medium only. After 4 days, the size of EGFP clones was counted and quantified; cell death events in each clone was assessed alive by propium iodide and Hoescht staining; differentiation states was examined by immunostaining with Nestin, Tuj1, RIP and GFAP. Another duplicate set of cultures was allowed to differentiate in the presence of RA $(0.5 \mu \mathrm{M})$ and FBS $(0.5 \%)$ for six days and the clonal composition ( $\mathrm{Tuj}^{+} / \mathrm{RIP}^{+} / \mathrm{GFAP}^{+}$) was examined for multipotentiality.

\section{Competing interests}

The authors declare that they have no competing interests.

\section{Authors' contributions}

DKM and KP: conception and design, collection of data, data analysis, manuscript writing; MS: original chimeric receptor constructs; GM and HS: conception and design, financial support, data analysis, manuscript writing.

\section{Additional material}

\section{Additional file 1}

FGF-2 promotes the self-renewal of both rodent and human NSCs. A. Sample images of mouse, rat and human NSCs cultured in the presence of FGF-2 and/or other growth factors. Scale bar: $20 \mu \mathrm{m}$. B. Sample images of rat NSCs in various conditions. Scale bar: $20 \mu \mathrm{m}$.

Click here for file

[http://www.biomedcentral.com/content/supplementary/17566606-2-16-S1.pdf] 


\section{Additional file 2}

Clonal analysis assay. A. A schematic diagram of clonal analysis assay B. Sample images and quantification of the effect of FGF-2 on clonal expansion. Scale bar: $20 \mu \mathrm{m}$.

Click here for file

[http://www.biomedcentral.com/content/supplementary/17566606-2-16-S2.pdf]

\section{Additional file 3}

Defective neuronal differentiation in PLC $\gamma 1$-depleted cells. Immunostaining of differentiated culture from adult NSCs with PLC $\gamma 1$ depleted. Shown are Tuj1 (A), DAPI (B), ZsGreen (C) and Merged image (D). Scale bar: $20 \mu \mathrm{m}$.

Click here for file

[http://www.biomedcentral.com/content/supplementary/17566606-2-16-S3.pdf]

\section{Additional file 4}

Model. A model of the intracellular signalling mechanisms by which FGF2 promotes the self-renewal of adult NSCs.

Click here for file

[http://www.biomedcentral.com/content/supplementary/17566606-2-16-S4.pdf]

\section{Acknowledgements}

We would like to thank J.O. Liu, D.D Ginty, S.H. Snyder and M. Bonaguidi for comments and suggestions, L-h. Liu for technical support, Drs. X. Yu and L. Cheng for help on flow cytometry, and A. Ghosh, S.H. Snyder, D.D. Ginty, and V. Dawson for reagents and assistance. This work was supported by the National Institute of Health (NS047344, AG024984, MH0840 I8), McKnight Foundation, NARSAD, The Robert Packard Center for ALS Research at Johns Hopkins and MDA, Maryland Stem Cell Research Fund and IMHRO to H.S. and by Maryland Stem Cell Research Fund to G.L.M. D.K. Ma was a pre-doctoral fellow of the American Heart Association.

\section{References}

I. Temple S: The development of neural stem cells. Nature 200I, 4 I 4(6859): I I2-I I 7.

2. Gage FH: Mammalian neural stem cells. Science 2000, 287(5457): | $433-1438$.

3. Alvarez-Buylla A, Seri B, Doetsch F: Identification of neural stem cells in the adult vertebrate brain. Brain Res Bull 2002, 57(6):75|-758.

4. Ma DK, Bonaguidi MA, Ming GL, Song H: Adult neural stem cells in the mammalian central nervous system. Cell Res 2009, 19(6):672-682.

5. Ming GL, Song $\mathrm{H}$ : Adult neurogenesis in the mammalian central nervous system. Annu Rev Neurosci 2005, 28:223-250.

6. Zhao C, Deng W, Gage FH: Mechanisms and functional implications of adult neurogenesis. Cell 2008, I32(4):645-660.

7. Duan X, Kang E, Liu CY, Ming GL, Song H: Development of neural stem cell in the adult brain. Curr Opin Neurobiol 2008, 18(I): 108-115.

8. Snyder EY, Macklis JD: Multipotent neural progenitor or stemlike cells may be uniquely suited for therapy for some neurodegenerative conditions. Clin Neurosci 1995, 3(5):310-316.

9. Bjorklund A, Lindvall O: Self-repair in the brain. Nature 2000, 405(6789):892-893.

10. Goh EL, Ma D, Ming GL, Song H: Adult neural stem cells and repair of the adult central nervous system. J Hematother Stem Cell Res 2003, I2(6):67I-679.

II. McKay RD: Stem cell biology and neurodegenerative disease. Philos Trans R Soc Lond B Biol Sci 2004, 359(1445):85I-856.
12. Morrison SJ, Shah NM, Anderson DJ: Regulatory mechanisms in stem cell biology. Cell 1997, 88(3):287-298.

13. Orford KW, Scadden DT: Deconstructing stem cell selfrenewal: genetic insights into cell-cycle regulation. Nat Rev Genet 2008, 9(2): II5-128.

14. Morrison SJ, Spradling AC: Stem cells and niches: mechanisms that promote stem cell maintenance throughout life. Cell 2008, 132(4):598-6II.

15. Molofsky AV, Pardal R, Morrison SJ: Diverse mechanisms regulate stem cell self-renewal. Curr Opin Cell Biol 2004, 16(6):700-707.

16. Reynolds BA, Weiss S: Generation of neurons and astrocytes from isolated cells of the adult mammalian central nervous system. Science 1992, 255(5052): I707-1710.

17. Kilpatrick TJ, Bartlett PF: Cloning and growth of multipotential neural precursors: requirements for proliferation and differentiation. Neuron 1993, I0(2):255-265.

18. Ghosh A, Greenberg ME: Distinct roles for bFGF and NT-3 in the regulation of cortical neurogenesis. Neuron 1995, I5(I):89-103.

19. Bikfalvi A, Klein S, Pintucci G, Rifkin DB: Biological roles of fibroblast growth factor-2. Endocr Rev 1997, 18(I):26-45.

20. Li X, Barkho BZ, Luo Y, Smrt RD, Santistevan NJ, Liu C, Kuwabara T, Gage $\mathrm{FH}$, Zhao $\mathrm{X}$ : Epigenetic regulation of the stem cell mitogen Fgf-2 by Mbd I in adult neural stem/progenitor cells. J Biol Chem 2008, 283(4I):27644-27652.

2I. Maric D, Maric I, Chang YH, Barker JL: Prospective cell sorting of embryonic rat neural stem cells and neuronal and glial progenitors reveals selective effects of basic fibroblast growth factor and epidermal growth factor on self-renewal and differentiation. J Neurosci 2003, 23(I):240-25I.

22. Palmer TD, Takahashi J, Gage FH: The adult rat hippocampus contains primordial neural stem cells. Mol Cell Neurosci 1997, 8(6):389-404.

23. Qian X, Shen Q, Goderie SK, He W, Capela A, Davis AA, Temple S: Timing of CNS cell generation: a programmed sequence of neuron and glial cell production from isolated murine cortical stem cells. Neuron 2000, 28(I):69-80.

24. Song H, Stevens CF, Gage FH: Astroglia induce neurogenesis from adult neural stem cells. Nature 2002, 4I7(6884):39-44.

25. Palmer TD, Ray J, Gage FH: FGF-2-responsive neuronal progenitors reside in proliferative and quiescent regions of the adult rodent brain. Mol Cell Neurosci 1995, 6(5):474-486.

26. Shihabuddin LS, Horner PJ, Ray J, Gage FH: Adult spinal cord stem cells generate neurons after transplantation in the adult dentate gyrus. J Neurosci 2000, 20(23):8727-8735.

27. Neumeister B, Grabosch A, Basak O, Kemler R, Taylor V: Neural progenitors of the postnatal and adult mouse forebrain retain the ability to self-replicate, form neurospheres, and undergo multipotent differentiation in vivo. Stem Cells 2009, 27(3):7|4-723.

28. Zheng W, Nowakowski RS, Vaccarino FM: Fibroblast growth factor $\mathbf{2}$ is required for maintaining the neural stem cell pool in the mouse brain subventricular zone. Dev Neurosci 2004, 26(24): $181-196$.

29. Tureyen K, Vemuganti R, Bowen KK, Sailor KA, Dempsey RJ: EGF and FGF-2 infusion increases post-ischemic neural progenitor cell proliferation in the adult rat brain. Neurosurgery 2005, 57(6): I254-1263. discussion I254-1263

30. Nakatomi H, Kuriu T, Okabe S, Yamamoto S, Hatano O, Kawahara N, Tamura A, Kirino T, Nakafuku M: Regeneration of hippocampal pyramidal neurons after ischemic brain injury by recruitment of endogenous neural progenitors. Cell 2002, I I 0(4):429-44I.

31. Ma YP, Ma MM, Cheng SM, Ma HH, Yi XM, Xu GL, Liu XF: Intranasal bFGF-induced progenitor cell proliferation and neuroprotection after transient focal cerebral ischemia. Neurosci Lett 2008, 437(2):93-97.

32. Frinchi M, Bonomo A, Trovato-Salinaro A, Condorelli DF, Fuxe K, Spampinato MG, Mudo G: Fibroblast growth factor-2 and its receptor expression in proliferating precursor cells of the subventricular zone in the adult rat brain. Neurosci Lett 2008, 447(I):20-25.

33. Gaughran F, Payne J, Sedgwick PM, Cotter D, Berry M: Hippocampal FGF-2 and FGFRI mRNA expression in major depres- 
sion, schizophrenia and bipolar disorder. Brain Res Bull 2006, 70(3):22I-227.

34. Yoshimura S, Teramoto T, Whalen MJ, Irizarry MC, Takagi Y, Qiu J, Harada J, Waeber C, Breakefield XO, Moskowitz MA: FGF-2 regulates neurogenesis and degeneration in the dentate gyrus after traumatic brain injury in mice. J Clin Invest 2003, I I 2(8): I 202-12I0.

35. Schmidt HD, Duman RS: The role of neurotrophic factors in adult hippocampal neurogenesis, antidepressant treatments and animal models of depressive-like behavior. Behav Pharmacol 2007, 18(5-6):39|-418.

36. Kalani MY, Cheshier SH, Cord BJ, Bababeygy SR, Vogel H, Weissman IL, Palmer TD, Nusse R: Wnt-mediated self-renewal of neural stem/progenitor cells. Proc Natl Acad Sci USA 2008, I05(44): I6970-I6975.

37. Ma DK, Jang MH, Guo JU, Kitabatake Y, Chang ML, Pow-Anpongkul $\mathrm{N}$, Flavell RA, Lu B, Ming GL, Song H: Neuronal activity-induced Gadd45b promotes epigenetic DNA demethylation and adult neurogenesis. Science 2009, 323(59 I7): 1074-1077.

38. Bonaguidi MA, Peng CY, McGuire T, Falciglia G, Gobeske KT, Czeisler C, Kessler JA: Noggin expands neural stem cells in the adult hippocampus. J Neurosci 2008, 28(37):9194-9204.

39. Ma DK, Kim WR, Guo L-M, Song H: Activity-dependent extrinsic regulation of adult hippocampal and olfactory bulb neurogenesis. Ann N Y Acad Sci 2009 in press.

40. Bauer S: Cytokine control of adult neural stem cells. Ann N Y Acad Sci 2009, I I 53:48-56.

4I. Xiao Z, Kong Y, Yang S, Li M, Wen J, Li L: Upregulation of Flk-I by bFGF via the ERK pathway is essential for VEGF-mediated promotion of neural stem cell proliferation. Cell Res 2007, I7(I):73-79.

42. Schlessinger J: Cell signaling by receptor tyrosine kinases. Cell 2000, $103(2): 211-225$.

43. Bottcher RT, Niehrs C: Fibroblast growth factor signaling during early vertebrate development. Endocr Rev 2005, 26(I):63-77.

44. Mohammadi M, Dionne CA, Li W, Li N, Spivak T, Honegger AM, Jaye $M$, Schlessinger J: Point mutation in FGF receptor eliminates phosphatidylinositol hydrolysis without affecting mitogenesis. Nature 1992, 358(6388):68I-684.

45. Zhao M, Li D, Shimazu K, Zhou YX, Lu B, Deng CX: Fibroblast growth factor receptor- $I$ is required for long-term potentiation, memory consolidation, and neurogenesis. Biol Psychiatry 2007, 62(5):38I-390.

46. Maric D, Fiorio Pla A, Chang YH, Barker JL: Self-renewing and differentiating properties of cortical neural stem cells are selectively regulated by basic fibroblast growth factor (FGF) signaling via specific FGF receptors. J Neurosci 2007, 27(8): $1836-1852$.

47. Jones NC, Fedorov YV, Rosenthal RS, Olwin BB: ERKI/2 is required for myoblast proliferation but is dispensable for muscle gene expression and cell fusion. J Cell Physiol 200I, 186(I):104-II5.

48. Burdon T, Chambers I, Stracey C, Niwa H, Smith A: Signaling mechanisms regulating self-renewal and differentiation of pluripotent embryonic stem cells. Cells Tissues Organs 1999, 165(3-4): $|3|-\mid 43$.

49. Lie DC, Song H, Colamarino SA, Ming GL, Gage FH: Neurogenesis in the adult brain: new strategies for central nervous system diseases. Annu Rev Pharmacol Toxicol 2004, 44:399-42I.

50. Suhonen JO, Peterson DA, Ray J, Gage FH: Differentiation of adult hippocampus-derived progenitors into olfactory neurons in vivo. Nature 1996, 383(660 I):624-627.

5I. Ong SH, Guy GR, Hadari YR, Laks S, Gotoh N, Schlessinger J, Lax I: FRS2 proteins recruit intracellular signaling pathways by binding to diverse targets on fibroblast growth factor and nerve growth factor receptors. Mol Cell Biol 2000, 20(3):979-989.

52. Lundin L, Ronnstrand L, Cross M, Hellberg C, Lindahl U, ClaessonWelsh L: Differential tyrosine phosphorylation of fibroblast growth factor (FGF) receptor-I and receptor proximal signal transduction in response to FGF-2 and heparin. Exp Cell Res 2003, 287(I): 190-198.

53. Favata MF, Horiuchi KY, Manos EJ, Daulerio AJ, Stradley DA, Feeser WS, Van Dyk DE, Pitts WJ, Earl RA, Hobbs F, et al:: Identification of a novel inhibitor of mitogen-activated protein kinase kinase. J Biol Chem 1998, 273(29): I8623-I8632.

54. Mansour SJ, Matten WT, Hermann AS, Candia JM, Rong S, Fukasawa K, Woude GF Vande, Ahn NG: Transformation of mammalian cells by constitutively active MAP kinase kinase. Science 1994, 265(5 174):966-970.

55. Cowley S, Paterson H, Kemp P, Marshall CJ: Activation of MAP kinase kinase is necessary and sufficient for $\mathrm{PCI} 2$ differentiation and for transformation of NIH 3T3 cells. Cell 1994, 77(6):84I-852.

56. Song HJ, Stevens CF, Gage FH: Neural stem cells from adult hippocampus develop essential properties of functional CNS neurons. Nat Neurosci 2002, 5(5):438-445.

57. Lobjois V, Benazeraf B, Bertrand N, Medevielle F, Pituello F: Specific regulation of cyclins DI and D2 by FGF and Shh signaling coordinates cell cycle progression, patterning, and differentiation during early steps of spinal cord development. Dev Biol 2004, 273(2): 195-209.

58. Gaiano N, Fishell G: The role of notch in promoting glial and neural stem cell fates. Annu Rev Neurosci 2002, 25:47 I-490.

59. Patterson RL, van Rossum DB, Ford DL, Hurt KJ, Bae SS, Suh PG, Kurosaki T, Snyder SH, Gill DL: Phospholipase C-gamma is required for agonist-induced $\mathrm{Ca2}+$ entry. Cell 2002, III(4):529-54I.

60. Piccirillo SG, Vescovi AL: Brain tumour stem cells: possibilities of new therapeutic strategies. Expert Opin Biol Ther 2007, 7(8): I I29-II35.

61. Louis DN: Molecular pathology of malignant gliomas. Annu Rev Pathol 2006, 1:97-II7.

62. Yamada M, Mizuguchi M, Rhee SG, Kim SU: Developmental changes of three phosphoinositide-specific phospholipase $C$ isozymes in the rat nervous system. Brain Res Dev Brain Res 1991, 59(1):7-16.

63. Ramirez-Castillejo C, Sanchez-Sanchez F, Andreu-Agullo C, Ferron SR, Aroca-Aguilar JD, Sanchez P, Mira H, Escribano J, Farinas I: Pigment epithelium-derived factor is a niche signal for neural stem cell renewal. Nat Neurosci 2006, 9(3):33I-339.

64. Karpowicz P, Willaime-Morawek S, Balenci L, DeVeale B, Inoue T, Kooy $D$ van der: E-Cadherin regulates neural stem cell selfrenewal. J Neurosci 2009, 29( I 2):3885-3896.

65. Fasano CA, Phoenix TN, Kokovay E, Lowry N, Elkabetz Y, Dimos JT, Lemischka IR, Studer L, Temple S: Bmi-I cooperates with Foxg I to maintain neural stem cell self-renewal in the forebrain. Genes Dev 2009, 23(5):561-574.

66. Ahn $\mathrm{S}$, Joyner $\mathrm{AL}$ : In vivo analysis of quiescent adult neural stem cells responding to Sonic hedgehog. Nature 2005, 437(7060):894-897.

67. Androutsellis-Theotokis A, Leker RR, Soldner F, Hoeppner DJ, Ravin R, Poser SW, Rueger MA, Bae SK, Kittappa R, McKay RD: Notch signalling regulates stem cell numbers in vitro and in vivo. Nature 2006, 442(7 I 04):823-826.

68. Shen Q, Goderie SK, Jin L, Karanth N, Sun Y, Abramova N, Vincent $P$, Pumiglia K, Temple S: Endothelial cells stimulate self-renewal and expand neurogenesis of neural stem cells. Science 2004, 304(5675): 1338-1340.

69. Lie DC, Colamarino SA, Song HJ, Desire L, Mira H, Consiglio A, Lein $E S$, Jessberger $S$, Lansford $H$, Dearie AR, et al.: Wnt signalling regulates adult hippocampal neurogenesis. Nature 2005, 437(7063): I370-1375.

70. Lai K, Kaspar BK, Gage FH, Schaffer DV: Sonic hedgehog regulates adult neural progenitor proliferation in vitro and in vivo. Nat Neurosci 2003, 6(I):2I-27.

7I. Song MR, Ghosh A: FGF2-induced chromatin remodeling regulates CNTF-mediated gene expression and astrocyte differentiation. Nat Neurosci 2004, 7(3):229-235.

72. Ge S, Goh EL, Sailor KA, Kitabatake Y, Ming GL, Song H: GABA regulates synaptic integration of newly generated neurons in the adult brain. Nature 2006, 439(7076):589-593.

73. Duan X, Chang JH, Ge S, Faulkner RL, Kim JY, Kitabatake Y, Liu XB, Yang CH, Jordan JD, Ma DK, et al.: Disrupted-In-Schizophrenia I regulates integration of newly generated neurons in the adult brain. Cell 2007, I 30(6): I | 46- I I 58.

74. Ma DK, Chiang CH, Ponnusamy K, Ming GL, Song H: G9a and Jhdm 2a regulate embryonic stem cell fusion-induced reprogramming of adult neural stem cells. Stem Cells 2008, 26(8):2|3|-2|4|. 